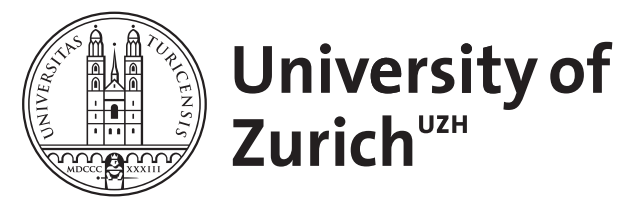

\title{
Reputation, group structure and social tensions
}

\author{
Rohner, Dominic
}

\begin{abstract}
Social tensions impede social cohesion and public goods provision, and can be a driving force for more serious conflicts such as civil wars. Surprisingly, the emergence of social tensions has been studied only rarely in the literature. In the present contribution a game-theoretic model highlights how reputation concerns and the structure of group cleavages matter for the emergence of social tensions. In particular, the respective effects of ethnic fractionalization, polarization and segregation are analyzed. The differences between ethnicity and class, and the role of social mobility are also studied. The predictions of the model can account for recent empirical evidence.
\end{abstract}

DOI: https://doi.org/10.1016/j.jdeveco.2010.10.008

Posted at the Zurich Open Repository and Archive, University of Zurich ZORA URL: https://doi.org/10.5167/uzh-57913

Journal Article

Accepted Version

Originally published at:

Rohner, Dominic (2011). Reputation, group structure and social tensions. Journal of Development Economics, 96(2):188-199.

DOI: https://doi.org/10.1016/j.jdeveco.2010.10.008 


\title{
Reputation, Group Structure and Social Tensions
}

\author{
Dominic Rohner \\ University of Zurich
}

November 4, 2010

\begin{abstract}
Social tensions impede social cohesion and public goods provision, and can be a driving force for more serious conflicts such as civil wars. Surprisingly, the emergence of social tensions has been studied only rarely in the literature. In the present contribution a game-theoretic model highlights how reputation concerns and the structure of group cleavages matter for the emergence of social tensions. In particular, the respective effects of ethnic fractionalization, polarization and segregation are analyzed. The differences between ethnicity and class, and the role of social mobility are also studied. The predictions of the model can account for recent empirical evidence.
\end{abstract}

JEL Classification: C72, D74, Z13.

Keywords: Conflict, Group Cleavages, Reputation, Ethnicity, Social Capital.

\footnotetext{
${ }^{0}$ Address: Department of Economics, University of Zurich, drohner@iew.uzh.ch.

Acknowledgments: I would like to thank two anonymous referees and the editor, Maitreesh Ghatak, for very valuable comments that have substantially improved the manuscript. I am also grateful to Toke Aidt, Samuel Bowles, Partha Dasgupta, Robert Evans, Michael Findley, Marcus Hagedorn, Masayuki Kudamatsu, John Miller, Karl Ove Moene, Massimo Morelli, David Myatt, Scott Page, Michelle Rendall, Maria Saez-Marti, Rajiv Sethi, Christopher Wallace, Jörgen Weibull, Diego Winkelried, Elizabeth Wood and Fabrizio Zilibotti for their helpful comments. Useful discussions with conference and seminar participants in Amsterdam, Santa Fe NM, Columbus OH, Chicago, London, Berlin, Oslo, New York, Paris, Oxford, Essex, York, Cambridge, Zurich, Warwick and Bern, and financial support from the Swiss National Science Foundation (SNF grant no. 100014-122636) are gratefully acknowledged. An earlier version of this paper has been circulated under the title "Information, Reputation and Ethnic Conflict".
} 


\section{Introduction}

In the absence of effective contract enforcement, low-level disputes over business can escalate and often result in significant social tensions ${ }^{1}$. As shown by Varshney (2001), such social tensions are particularly likely to arise in areas that are ethnically heterogeneous, and where most social interaction takes place within groups.

History tells us that social tensions in ethnically heterogeneous societies can have very serious consequences. Not only do they threaten social cohesion and impede collective goods provision (see e.g., Alesina et al., 1999; Miguel and Gugerty, 2005), but they can take the form of spontaneous riots or communal violence, and can even develop into full-blown civil war (cf. for example Brubaker and Laitin, 1998; Horowitz, 2000, 2001). ${ }^{2}$

In this paper we build a model of social tensions. Our starting point is the economic interaction between individual players, who match randomly and have to choose between cooperation or defection. Each player lives for two periods, and discounts the future. Players have imperfect information about the "type" of the other players, and the solution concept is the Perfect Bayesian Equilibrium. For some category of players (i.e., "strong" types) defection leads to high short-run gains, but with positive probability results in a bad reputation in the following period, making it harder to find a business partner. If this reputation cost of foregone trade gains is large enough, strong types are induced to cooperate and social tensions are low.

The likelihood that the match in the second period is informed about the past defection plays a crucial role for the reputation cost of defection. We derive this probability endogenously, based on the number and sizes of the different ethnic groups in the society and their frequency of interaction. It is assumed that players spend more than a proportional share of their time with people from their own ethnic group. Hence, it is more likely that the second-period match is informed if the victim of a first-period defection comes from the same ethnic group. Thus, it is more costly to defect on someone of the same group, and we easily establish that on average there are more social tensions (defined as number of defections divided by total matches) occurring between groups than within groups.

This simple framework yields a rich set of novel comparative static results on the impact of group structure on individual incentives for cooperation: First, we find that it is less costly to defect on a trade partner from another group in a more polarized society (i.e., with two ethnic groups of similar size). Intuitively, since none of the group sizes becomes very small, none of the conditional probabilities of being informed becomes very high.

Ethnic segregation (i.e., the own-group bias in matching) has subtle implications. Due to monitoring effects, within-group social tensions decrease and between-group ten-

\footnotetext{
${ }^{1}$ Cf. Horowitz (2000), Boehm (1986) and Tambiah (1990) for accounts of how individual disputes can lead to widespread social tensions.

${ }^{2}$ Horowitz (1973: 1) gives the following example: "In May and again in September 1966, mobs of Northern Nigerians set about attacking Ibo residing in the North. These massive killings were important steps on the road to a powerful Ibo secessionist movement in Eastern Nigeria and nearly three years of civil war".
} 
sions increase in more segregated societies. The impact on the total number of defections, however, is ambiguous. In societies with high incentives for defection a marginal increase in segregation can reduce the total number of disputes.

Ethnic fractionalization (i.e., the total number of groups) reduces the incentives for within-group defection (as groups become smaller, monitoring is better), but makes defection more likely in between-group matches (if there are many other ethnic groups, a bad reputation in one of them has only small costs).

Further, we study how the results differ when the dividing line in society is class rather than ethnicity. Contrary to ethnicity, class is not "immutable", i.e., if the economy features some social mobility people can change class. The probability of switching groups moderates the incentives for between-group defections, and we predict fewer social tensions between classes than between ethnic groups, and find that the qualitative effects of increases in social mobility are similar to decreases in segregation.

This framework fits well many real world settings, as illustrated by some examples. Bates (2010), partially based on Evans-Pritchard (1940), gives an account of the Nuer, who are pastoral people in Southern Sudan. Most of their economic interactions are about cattle, with the risk of theft and dishonest business ("defection") held in check by concerns about bad reputation and future disadvantages. These incentives usually are sufficient to prevent dishonest business within the tribe, but often are too weak to guarantee cooperation in between-tribe interactions: "Insofar as the Nuer raided cattle, they tended to raid the cattle of others; raids within the tribe were rare" (Bates, 2010: 28). Accordingly, social tensions are observed mostly between tribes, but rarely within.

Horowitz (2000) points out that there are fewer defections in individual interactions among people from the same ethnic group: "Common ethnicity enhances the predictability of (...) behavior and imposes a set of normative obligations on transactions" (2000: 81). He also provides several examples where business disputes between individuals from different ethnic groups resulted in significant social tensions, e.g., business disputes between Sinhalese and Tamil merchants in Sri Lanka, between Assamese, Bengali and Marwaris traders in the Indian state of Assam, between Ivorians and Mossi in Ivory Coast, and between Chinese and Malay in Malaysia. Horowitz provides similar examples for Uganda, Kenya, Philippines and different parts of India. Likewise, individual level business disputes led to social tensions between the Pathan and Bihari ethnic groups, fueling Pakistan's Karachi riots in 1985 (Tambiah, 1990).

Surprisingly, the emergence of social tensions has received little attention in the theoretical literature. The most closely related paper is by Lester (2005) and models the incentives for forming groups, where the main trade-off is between groups being able to sustain cooperation, and the anonymous market offering more lucrative trades. In his framework all groups need to be the same size (since otherwise some agents would switch groups) and the individual decisions in equilibrium, i.e., "trust" in group matches versus "trade" in the anonymous market, do not depend on the number of groups and their size. Hence, it is not possible in such a setting to study the impact of group structures on individual defection and social tensions, which is the goal of our paper.

A classic finding in the conflict literature states that there are two necessary condi- 
tions for the onset of civil war: 1) the existence of social tensions and grievances, 2) the feasibility of collective action to transform tensions into fighting (e.g., Gurr, 1970, 1993; Hegre et al., 2001). While the current paper focuses on the first of the two conditions, the emergence of social tensions, all other formal models of social conflict focus on the second, collective action and group-level contest. Esteban and Ray (2008a) show that the right combination of time and resources invested into contest makes mobilization and alliance formation easier for ethnic than for class conflict. In other papers, Esteban and Ray (1999, 2008b, 2009) relate indicators of polarization and fractionalization to contests between groups. They find that in a collective action framework the total resources groups spend on conflict can be approximated as a weighted average of three widely used indices of inequality, fractionalization and polarization. Also Robinson (2001) models conflict on the group level and inquires under what conditions ethnic conflict is more or less salient and destructive than class conflict. Caselli and Coleman II (2010) study interaction between different groups, and find that ethnicity enforces coalition membership and thereby increases the expected payoffs of conflict. ${ }^{3}$

All these theoretical papers focus on aggregate rather than on individual players. While in contrast to our setting they cannot account for high social tensions, low trust and low public good provision in ethnically divided societies, they explore mechanisms for how ethnic social tensions can translate - through collective action and mobilization - into full-blown ethnic wars.

The present framework also builds on the literature on commitment, reputation and contract enforcement in trade and business (see Greif et al., 1994; Tirole, 1996; Dixit, 2003) ${ }^{4}$. Fearon and Laitin (1996) emphasize intra-group enforcement of group members' cooperation with players from other ethnic groups. Anderson et al. (2009) study the enforcement of roscas. In contrast to these papers we analyze the effects of group structure on individual cooperation.

Also the literature on "social capital" is relevant (cf. Putnam et al., 1993; Knack and Keefer, 1997). It is still controversial what this term precisely means and what it should include. In the pioneering work of Putnam et al. (1993) social capital was defined very broadly and included all "features of social organization, such as trust, norms and networks, that can improve the efficiency of society by facilitating coordinated actions" (1993: 167). Similarly broad is Coleman's (1988: S98) classic functionalist definition of social capital as "not a single entity but a variety of different entities, with two elements in common: they all consist of some aspect of social structures, and they facilitate certain actions of actors". Both of these definitions, and most of the literature, stress an essentially positive view of social capital.

Dasgupta (2005: S10) argues against catch-all definitions of "social capital", which he defines "to mean interpersonal networks, nothing more". The key concept in his thinking is "trust", which is crucial for economic transactions, but needs to be rationally

\footnotetext{
${ }^{3}$ Also Strulik (2008) links ethnic diversity and group-level contest.

${ }^{4}$ There are also literatures on image scores and cooperation (e.g., Nowak and Sigmund, 1998) and on sustaining cooperation in PD games with repeated matching (e.g., Kandori, 1992). Both of these literatures study homogeneous societies without group cleavages.
} 
justifiable, i.e., the other player must have incentives to be trustworthy (Dasgupta, 1988, 1999). "Social capital" (i.e., "social networks") in some situations can lead to trust because it can give incentives to honor contracts. However, in Dasgupta's (2005) view, social networks can have also a "dark side" and be exclusive, exploitative or inefficient.

This way of thinking connects well with our model, where ethnic networks imply that players match more than proportionally with other players of their own group. This feature can induce "trust" (i.e., beliefs about reputation costs of the opponent that sustain cooperation) in within-group interactions, but it reduces trust in players from other groups. Hence, there is less social cooperation in ethnically divided societies (i.e., more "defections" in the model). Our predictions are in line with the empirical evidence: A more fractionalized group structure has been shown to result in less civic participation (Alesina and La Ferrara, 2000; Vigdor, 2004), less trust (Alesina and La Ferrara, 2002) and less public goods provided (Alesina et al., 1999; Luttmer, 2001; Miguel and Gugerty, 2005; Lind, 2007).

Also the literature on civil wars is related. Vanhanen (1999), Ellingsen (2000), Sambanis (2001), Hegre et al. (2001), Collier and Rohner (2008) and Collier et al. (2009) find that ethnic heterogeneity and fractionalization increase the risk of civil wars and other forms of political violence. ${ }^{5}$

In contrast, Reynal-Querol (2002) and Montalvo and Reynal-Querol (2005) conclude that ethnic conflict is not driven by fractionalization, but by polarization.

Further, some scholars argue that segregation increases the risk of ethnic conflict (Diez Medrano, 1994; Olzak et al., 1996), while others stress that segregation, taking the form of "partition", could be a solution to ethnic conflict (Horowitz, 2000) ${ }^{6}$.

The remainder of the paper is organized as follows. Section 2 builds a basic model of cooperation and defection for a homogeneous society. In section 3, group structure is introduced in the model, and the impact of polarization and segregation assessed. The model is extended to n-groups in section 4 and the effects of fractionalization are studied. Section 5 extends the model to class conflict and social mobility, and section 6 concludes.

\section{Reputation and Social Tensions in a Homogeneous So- ciety}

This section builds a simple framework that shows how concerns about reputation are linked to the emergence of social tension. We start with the case of a homogeneous society, then introduce ethnic divisions in the following section.

In particular, we focus on explaining whether the economic interaction between players is characterized by "defection" or "cooperation"7. The concepts of "defection" and "social tension" are linked in the following way.

\footnotetext{
${ }^{5}$ In Fearon and Laitin (2003) and Collier and Hoeffler (2004) ethnic fractionalization is not found to increase the risk of civil war.

${ }^{6}$ Sambanis (2000) concludes that partition does not significantly prevent conflict.

${ }^{7}$ These concepts are defined more formally under assumption G.2 below.
} 
Definition 1 Social tension is defined as "number of matches with defection" divided by "total number of matches".

The more players defect, the higher the level of social tensions.

\subsection{Assumptions}

Below are listed the main assumptions and features of the basic model.

G.1 - General setting: The game lasts for an infinite number of periods. A large number of players match in pairs of two in each period. Each player lives for two periods and discounts the future. When a player dies after the second period, a new player is born. Players being in their first period match with other players being in their first period, and players in their second period match with other players in their second period. This assumption simplifies the analysis, but could be dropped without affecting the results. New pairs form randomly in each period (it is possible, although unlikely, to match with the same opponent as in the first period).

G.2 - Actions: First, players choose between entering into contact with the opponent or staying out, o. If players enter, they select between cooperation, $\mathrm{c}$, or defection, $\mathrm{d}$. Thus, $a \in\{c, d, o\}$.

G.3 - Types: There are "strong" types, s, and "weak" types, w. Thus, $t \in\{s, w\}$. A proportion $p$ of players are assumed to be strong.

G.4 - Payoff function: The payoff received is labeled $\pi_{a a}^{t}$, where the superscript t refers to the type, the left subscript refers to the player's own action, while the righthand side subscript refers to the opponent's action. For example, the payoff of a weak player who cooperates and matches with an opponent who defects is labeled $\pi_{c d}^{w}$.

For simplicity we will focus on a reduced form of profits from interaction ${ }^{8}$. It is assumed that whenever at least one player stays out there is no interaction and both players of a match receive an outside option payoff equal to zero. Formally, $\pi_{o a}^{t}=\pi_{a o}^{t}=$ 0 . The payoffs of some player $i$ of type $t$ in a one shot game are summarized in Figure 1.

It is assumed that for weak players the payoff structure is such that cooperation would be a dominant strategy in a one-shot game and that they are better off staying out whenever their opponent defects. Thus, $\pi_{c c}^{w}>\pi_{d c}^{w}, \pi_{c d}^{w}>\pi_{d d}^{w}, \pi_{c c}^{w}>0>\pi_{c d}^{w}$.

For strong types the payoff structure is such that defection is the dominant strategy in a one-shot game: $\pi_{d c}^{s}>\pi_{c c}^{s}, \pi_{d d}^{s}>\pi_{c d}^{s}$. Further, it is assumed that strong types would always have incentives to enter the game: $\pi_{a a}^{s}>0, \forall a a \in\{c c, d c, c d, d d\}$.

G.5 - Information: Players have incomplete knowledge about the type of their opponent in both periods, but they know the distribution of types, i.e., $p$ is common

\footnotetext{
${ }^{8}$ Various forms of intuitive contest success functions would be consistent with the features included under G.4. This is for example the case for a simple difference-form contest success function: $V_{i}=$ $\left(\frac{1}{2}+\theta\left(\rho F_{i}-\psi F_{j}\right)\right) S-c F_{i}-g F_{j}$, where $\mathrm{i}, \mathrm{j}=$ players, $\theta=$ parameter capturing the decisiveness of fighting effort (with $0 \leq \theta \leq 0.5), \rho=$ parameter indicating the fighting strength of player $\mathrm{i}(0 \leq \rho \leq 1)$, $F=$ level of fighting effort $(0 \leq F \leq 1), \psi=$ fighting strength of player $\mathrm{j}(0 \leq \psi \leq 1), S=$ economic gains (surplus) from interaction, $c=$ parameter related to the cost of player i's fighting effort, and $g=$ parameter measuring player i's cost inflicted by the fighting effort of player $\mathrm{j}$.
} 


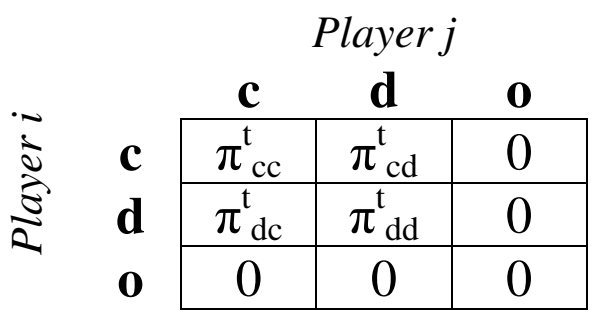

Figure 1: Matrix of player i's payoffs

knowledge. When a player defects on an opponent who cooperates, a proportion $q$ of the population get informed about the bad behavior (where $0<q<1$ ). When both players of a match defect or if no defection occurs, nobody gets informed. Formally, we have a signal $\sigma \in\{0,1\}$, where informed players receive a signal $\sigma=1$, while uninformed players receive $\sigma=0$.

G.6 - Beliefs: Players have rational beliefs and do Bayesian updating. They believe that with probability $\mu$ their current opponent is strong. In the first period when there is no a priori information about the type of the opponent players, beliefs simply correspond to the prior, $\mu=\frac{p}{p+(1-p) t_{w}}$, where $t_{w}=$ proportion of weak players entering the game. To make the analysis interesting, we assume that $p<\mu^{*}$ (a formal derivation of the threshold level $\mu^{*}$ will follow further below), and that accordingly a weak type would have incentives to enter the game in the first period, whenever her fellow weak players enter.

In what follows we will focus on the solution of the game when "uninformed" weak players enter the game in the first period, $t_{w}=1$, leading to $\mu=p<\mu^{*}$. There always exists another equilibrium in pure strategies, which is less relevant to our research question, when all weak players stay out, decreasing thereby the expected value of entering for fellow weak players.

Similarly, it is assumed that the probabilities are such that weak types also have incentives to enter the game in the second period if they receive no signal, $(\mu \mid \sigma=$ $0)<\mu^{*}$. Like for the first period, we focus on the equilibrium in which they do so, not discussing in detail a situation when all weak players stay out (which, again, is less relevant to our research question). The beliefs are derived in more detail further below.

G.7 - Solution concept: Perfect Bayesian Equilibrium in pure strategies.

\subsection{Results}

We shall solve this first building block of the model through backward induction. The behavior in the second period of the players' lives is as follows:

Lemma 1 In her second period of life a strong player will always defect. 
Proof. In the second period there is no shadow of the future and players behave as in a one-shot game. Given $\pi_{d c}^{s}>\pi_{c c}^{s}, \pi_{d d}^{s}>\pi_{c d}^{s}$, strong players will always defect, a=d.

A similar reasoning applies to weak players. The condition for which a weak player would prefer $\mathrm{a}=\mathrm{c}$ to $\mathrm{a}=\mathrm{o}$ in her second period is as follows:

$$
\mu \pi_{c d}^{w}+(1-\mu) \pi_{c c}^{w}>0
$$

After reformulation we obtain the threshold level $\mu^{*}=\frac{\pi_{c c}^{w}}{\pi_{c c}^{w}-\pi_{c d}^{w}}$. Thus, if $\mu<\mu^{*}$, a weak player prefers a $=\mathrm{c}$. Note that $0<\mu^{*}<1$ always holds, given that $\pi_{c c}^{w}>0$ and $\pi_{c d}^{w}<0$.

Lemma 2 In her second period of life a weak player will never defect. She will stay out, whenever $\mu \geq \mu^{*}$, and will enter and cooperate for $\mu<\mu^{*}$.

Proof. In the second period there is no shadow of the future and players behave as in a one-shot game. Given $\pi_{c c}^{w}>\pi_{d c}^{w}, \pi_{c d}^{w}>\pi_{d d}^{w}$, weak players will never have incentives to defect. As shown above a weak player is better off playing $\mathrm{a}=\mathrm{c}$ rather than $\mathrm{a}=\mathrm{o}$ if and only if $\mu<\mu^{*}{ }^{9}$

Now we can analyze the actions chosen in the first period of weak players' lives.

Lemma 3 In her first period of life a weak player always enters and cooperates.

\section{Proof. See Appendix.}

To make the analysis interesting, we made the assumption G.6. This rules out situations where weak players always stay out in their second period and where accordingly strong players never have incentives to cooperate. Before deriving the strong players' optimal action in period 1, we shall analyze in more detail the beliefs.

The beliefs are updated using Bayes' rule. It follows from lemma 3 that weak players never defect in their first period. For observing $\sigma=1$ the beliefs are as shown below.

$$
(\mu \mid \sigma=1)=\frac{p z_{s}\left(1-p z_{s}\right) q}{p z_{s}\left(1-p z_{s}\right) q}=1
$$

where $z_{s}=$ proportion of strong types that defect in their first period.

If $z_{s}=0$, this expression is not defined and Bayes' rule cannot be used. Only the off-equilibrium beliefs $(\mu \mid \sigma=1) \geq \mu^{*}$ are consistent. For $(\mu \mid \sigma=1)<\mu^{*}$ weak players choose $\mathrm{a}=\mathrm{c}$, which gives incentives to strong types to always choose $\mathrm{a}=\mathrm{d}$. Accordingly, the beliefs for this case should be $(\mu \mid \sigma=1)=1$, making the beliefs $(\mu \mid \sigma=1)<\mu^{*}$ inconsistent. For observing $\sigma=0$, the beliefs are:

\footnotetext{
${ }^{9}$ For simplicity, we adopt the tie-breaking rule that weak players stay out if they are indifferent between $\mathrm{a}=\mathrm{O}$ and $\mathrm{a}=\mathrm{c}$.
} 


$$
(\mu \mid \sigma=0)=\frac{p\left(1-z_{s}\right)+p z_{s}\left(1-\left(1-p z_{s}\right) q\right)}{(1-p)+p\left(1-z_{s}\right)+p z_{s}\left(1-\left(1-p z_{s}\right) q\right)}
$$

Given that $(\mu \mid \sigma=1)=1$, it follows directly from lemma 2 that whenever a weak player observes $\sigma=1$ in her second period, she will stay out. In contrast, following assumption G.6, $(\mu \mid \sigma=0)<\mu^{*}$ and after observing $\sigma=0$ weak players will choose $\mathrm{a}=\mathrm{c}$ in the second period. This represents the reputation cost of defection in the first period for a strong player: After selecting $\mathrm{a}=\mathrm{d}$ in her first period, a given strong player may have difficulties finding a business partner in her second period.

Now we shall derive the optimal action of strong players in their first period.

$$
\begin{gathered}
E\left(\pi_{d a}^{s}\right)=z_{s} \mu \pi_{d d}^{s}+\left(1-z_{s} \mu\right) \pi_{d c}^{s}+\delta\left[p \pi_{d d}^{s}+\left(1-\left(1-z_{s} \mu\right) q\right)(1-p) \pi_{d c}^{s}\right] \\
E\left(\pi_{c a}^{s}\right)=z_{s} \mu \pi_{c d}^{s}+\left(1-z_{s} \mu\right) \pi_{c c}^{s}+\delta\left[p \pi_{d d}^{s}+(1-p) \pi_{d c}^{s}\right]
\end{gathered}
$$

where $\delta=$ discount rate, $E$ refers to expected value.

We know that in the first period (when there are no signals), the beliefs simply correspond to the prior, i.e., $\mu=p$. After reformulation we obtain the condition for which $E\left(\pi_{d a}^{s}\right)>E\left(\pi_{c a}^{s}\right)$ :

$$
z_{s} p\left[\pi_{d d}^{s}-\pi_{c d}^{s}\right]+\left(1-z_{s} p\right)\left[\pi_{d c}^{s}-\pi_{c c}^{s}\right]>\delta q\left(1-z_{s} p\right)(1-p) \pi_{d c}^{s}
$$

Equation (6) above is intuitive. Defection is worthwhile if the short-run gains from defection (left-hand side) are larger than the opportunity cost of foregone trade due to a bad reputation in the second period (right-hand side). As a tie-breaking rule it is assumed that players choose cooperation whenever they are indifferent. Equation (6) can be expressed in terms of $q$ :

$$
q<\frac{z_{s} p\left[\pi_{d d}^{s}-\pi_{c d}^{s}\right]+\left(1-z_{s} p\right)\left[\pi_{d c}^{s}-\pi_{c c}^{s}\right]}{\delta\left(1-z_{s} p\right)(1-p) \pi_{d c}^{s}} \equiv q^{*}
$$

The variable $q$ relates to the reputation cost of defection. If $q<q^{*}$, defection is worthwhile. Please note that for $q<q^{*}$ it must be that $z_{s}=1$. There can be multiple equilibria.

Lemma 4 In her first period of life a strong player always enters and cooperates if $q \geq q^{*}$, while she enters and defects for $q<q^{*}$.

Proof. This follows from equation (7).

Combining the results of the lemmas 1 to 4 we obtain the solution of the game described below in proposition 1 . 
Proposition 1 The following strategies constitute the unique Perfect Bayesian Equilibrium for all "uninformed" weak players entering the game. The weak types play $(a=c$; $\mu=p$ ) in the first period. In the second period, weak players select $\left(a=o ; \mu \geq \mu^{*}\right)$ for $\sigma=1$, and $\left(a=c ; \mu=\frac{p\left(1-z_{s}\right)+p z_{s}\left(1-\left(1-p z_{s}\right) q\right)}{(1-p)+p\left(1-z_{s}\right)+p z_{s}\left(1-\left(1-p z_{s}\right) q\right)}\right)$ for $\sigma=0$. In the first period strong types play $(a=d ; \mu=p)$ for $q<q^{*}$, and play $(a=c ; \mu=p)$ for $q \geq q^{*}$. In the second period strong types select ( $a=d$; with the same beliefs as the weak types).

Proof. Follows from the lemmas 1 to 4 .

Intuitively, proposition 1 describes a setting in which "weak" players are only willing to enter in a trade relationship if it is quite likely that their opponent will not cheat on them. The probabilities and beliefs are constructed such that without any negative information about their trade partner they are willing to take the risk and will agree to trade. Thus, "strong" players face a trade-off between being honest in the first period and benefiting from a good reputation in the second period, or cheating in the first period. In this latter case they receive some immediate gain in the first period, but have with some probability a bad reputation in the second period, which makes it harder to find a trading partner. Whether cheating is worthwhile depends on how likely the information about the bad behavior spreads. This is captured by the variable $q$. If this "information likelihood" $q$ of defection is high enough, social tensions are small.

Note that one interesting implication of this result is that following progress in technological possibilities of communication (which lead to a larger $q$ ), we should expect social tensions to decline. This prediction of the model is consistent with the empirical finding that industrialized countries are less likely to experience conflict (cf. Fearon and Laitin, 2003; Collier and Hoeffler, 2004).

In a homogeneous society the variable $q$ was just regarded as a constant. In ethnically divided societies $q$ becomes endogenous, as discussed in the following section.

\section{Introducing Group Cleavages in the Model}

In homogeneous societies the probability $q$ that the match in the second period is informed about the defection in the first period simply corresponds to the number of players getting informed $m$ divided by the total number of players $n$ in a society, $q=m / n \equiv k .{ }^{10}$ Intuitively, we can think of the informed players as "friends". For example, if some player has ten friends in a community of a hundred people, $q$ would equal 0.1 .

In ethnically divided societies the probabilities of the match in the second period being informed about one's defection differs depending on whom one defects on. We make the following assumptions to include group structure.

G.8 - Two groups: Initially, we assume that the population is composed of two groups, $\mathrm{i}$ and $\mathrm{j}$, which differ in ethnic characteristics (in section 4 the model will be

\footnotetext{
${ }^{10}$ To be precise, $q$ corresponds to the likelihood of "information dissemination" after defection on an opponent who cooperates (cf. G.5). For simplicity we will in the remainder of the paper just refer to $q$ as information dissemination after defection (while meaning defection on a cooperating opponent).
} 
extended to n-groups). The first group i amounts to a share $w$ of the whole population $(0<w<1)$. Accordingly, the part $v=(1-w)$ of the population belongs to group $\mathrm{j}$.

G.9 - Intense intra-group interaction: Players spend more than the proportional part of their time for interaction with their own ethnic group. In fact, there are two broad categories of activities people engage in: First, activities where matching is independent of group size, and, second, activities where people match with others proportional to group size.

The first category can be further divided into two sub-categories: cultural/religious activities and ethnic business dominance/monopolies. In particular, people belong to ethnic contact networks (cf. Horowitz, 2000; Rauch, 2001; Dustmann et al., 2010) and spend some important share of their time for ethnic cultural events, religious ceremonies, tribal gatherings etc.

Further, some economic activities are dominated by particular ethnic groups (cf. Horowitz, 2000, for a survey of the abundant literature on this). According to Horowitz (2000: 108), "the concentration of particular ethnic groups in particular sectors of the economy and in particular occupations within sectors is a feature of many societies (...)". Tambiah (1990) gives the example of the transport business in Karachi that is the ethnic monopoly of the Pathans. Often past colonial policies ${ }^{11}$ or cultural and religious factors ${ }^{12}$ were the initial sources of this specialization, but even centuries after the initial sources of distortion have been removed, substantial ethnic division of labor persists (Horowitz, 2000).

Crucially, during the time a player spends for cultural and religious events and ethnically dominated economic activities, she meets only players from these given ethnic groups, independently of the relative group sizes (i.e., a player spends constant parts of her time for these activities, even if the sizes of the involved ethnic groups change). However, a player spends the remainder of her time for activities that are not ethnicity specific, and for which she has intra- or inter-group interactions proportionally to the relative group sizes.

Formally, people spend a fixed part of time $d_{i}$ on within-group interaction, i.e., for ethnicity-specific cultural and religious events and for economic activities that are dominated by their own ethnic group. Similarly, people spend a smaller fixed part of time $e_{i}$ for between-group interaction, i.e., for economic activities that are dominated by the other group. The rest of their time, $\left(1-d_{i}-e_{i}\right)$, is spent proportionally to group sizes.

Clearly, $d_{i} \gg e_{i}$. This reflects the empirical evidence that intra-group interaction is typically much more frequent than inter-group interaction (cf. for example Fearon and

\footnotetext{
${ }^{11}$ For example, "in Malaysia, Chinese were encouraged to enter to mine tin and to trade, Indians to tab rubber, Ceylonese to run the railroads. In Trinidad, Guyana, Fiji, and Mauritius, Indians were imported to cut sugar cane" (Horowitz, 2000: 109).

${ }^{12}$ For example, pilgrimages to Mecca favored the dominant Muslim position in trade in Medieval times (Jha, 2008), and the Jewish dominance in Medieval lending was related to the fact that "the Church's ban on lending money at interest did not apply to Jews, who were considered to be outside the Christian community" (Bottincini, 2000).
} 
Laitin, 1996; Horowitz, 2000; Varshney, 2001). ${ }^{13}$

The probabilities of meeting a player belonging to the same group i, $P(S)$, resp. of meeting a player belonging to the other group $\mathrm{j}, P(D)$, become:

$$
\begin{gathered}
P(S)=d_{i}+\left(1-d_{i}-e_{i}\right) w \\
P(D)=e_{i}+\left(1-d_{i}-e_{i}\right)(1-w)
\end{gathered}
$$

where $w=$ population share of the player's own group $(0<w<1)$. The expressions are analogous for group $\mathrm{j}$.

Note that $P(S)=1-P(D)$. Given the evidence mentioned above we want to focus on situations where indeed players spend more than a proportional share of their time for within-group interaction, i.e., where $P(S)>w$. This is the case, as long as $d_{i}>e_{i} \frac{w}{1-w}$. We assume that this always holds.

This greater intensity of contact is the channel through which ethnicity matters in the present framework. If people were equally likely to match with people from any group, ethnicity would not play a role. This contact intensity also distinguishes ethnicity from other potential group characteristics such as, say, size, which are not salient in conflicts.

Our model allows for different levels of $d$ and $e$ for different groups, and this general case will also be emphasized for the analysis of intra-group interaction and for comparing the likelihood of within- versus between-group tension. For the comparative statics on inter-group interaction, however, we will make for expositional ease the non-critical assumption that all groups have the same level of $d_{i}=d_{j} \equiv d$, resp. $e_{i}=e_{j} \equiv e$.

G.10 - Matching: For some values of $d, e$ and $w$, not all players are matched with a trade partner. Without loss of generality we can assume the existence of some compensation package that leaves non-matched and other players in the same situation as if everybody had found a match.

\subsection{The Likelihood of Intra-Group and Inter-Group Tension}

First, we shall derive the probability of the second period's match being informed when a given player defects on someone of her own group. This probability is labeled $q_{S}$ :

$$
q_{S}=P(S) P(m \mid S)+P(D) P(m \mid D)
$$

where, $P(S)=$ Probability of meeting a player belonging to the same group, $P(m \mid$ $S)=$ Probability of the match being informed, conditional on being from the same group, $P(D)=$ Probability of meeting a player belonging to another group, $P(m \mid D)=$ Probability of the match being informed, conditional on being from another group.

Given (8) and (9), the conditional probabilities become:

\footnotetext{
${ }^{13}$ As an illustration, in the 2001 German Socio-Economic Panel $62 \%$ of non-Germans (who were $15 \%$ of the sample) indicated that their best friend was non-German, while only $4 \%$ of Germans had a non-German as their best friend (Dustmann et al., 2010).
} 


$$
P(m \mid S)=\frac{\left(d_{i}+\left(1-d_{i}-e_{i}\right) w\right) m}{w \cdot n}=\frac{d_{i}+\left(1-d_{i}-e_{i}\right) w}{w} k
$$

where $k=m / n$.

$$
P(m \mid D)=\frac{\left(e_{i}+\left(1-d_{i}-e_{i}\right)(1-w)\right) m}{(1-w) n}=\frac{e_{i}+\left(1-d_{i}-e_{i}\right)(1-w)}{(1-w)} k
$$

Introducing (8), (9), (11) and (12) in (10), we obtain the overall probability of the next match being informed after intra-group defection:

$$
q_{S}=k\left[\frac{d_{i}^{2}}{w}+\frac{e_{i}^{2}}{1-w}+1-\left(d_{i}+e_{i}\right)^{2}\right]
$$

For inter-group defection, the overall probability, $q_{D}$, of the next match being informed equals again the right-hand side of equation (10), and $P(S)$ and $P(D)$ are the same as before (see (8), resp., (9)). The new conditional probabilities become:

$$
\begin{gathered}
P(m \mid S)=\frac{e_{j}+\left(1-d_{j}-e_{j}\right) w}{w} k \\
P(m \mid D)=\frac{d_{j}+\left(1-d_{j}-e_{j}\right)(1-w)}{(1-w)} k
\end{gathered}
$$

Introducing (8), (9), (14) and (15) into (10), we obtain (16), which is the overall probability of the next match being informed after inter-group defection.

$$
q_{D}=k\left[\frac{d_{i} e_{j}}{w}+\frac{d_{j} e_{i}}{1-w}+1-\left(d_{i}+e_{i}\right)\left(d_{j}+e_{j}\right)\right]
$$

Note that we focus on relatively small levels of $k$, to make sure that all probabilities are well-defined between 0 and 1.

The variables of $q_{S}$ and $q_{D}$ correspond to the likelihood of the next opponent being informed in the case of within-group, resp. between-group defection. The reputational costs of defection are monotonically increasing in this likelihood of "information dissemination". The following numerical example illustrates the equations above.

Example 1 There is a population $n$ of 100 people, and every player has 10 friends $(m=10)$ whom she informs in case of defection. Thus, $k=0.1$. Half of the population are from group $A, w=0.5$, the other half from group B. Players spend, say, $40 \%$ of their time for strict within-group activities $(d=0.4)$, and $5 \%$ of their time for activities that necessarily involve the other group $(e=0.05)$. The rest of their time they spend according to population sizes. This implies that players end up spending $67.5 \%$ of their time interacting with people from their own group $(P(S)=0.675)$ and $32.5 \%$ of their time interacting with people from the other group $(P(D)=0.325)$. Thus, we obtain the following probability $q_{S}$ that the future match of a player is informed after within-group defection: $q_{S}=0.112$. In contrast, after between-group defection, $q_{D}=0.088$. 
As shown in the proposition below $q_{S}>q_{D}$ holds for any parameter values.

Proposition 2 The "information dissemination" of intra-group defection, $q_{S}$, is greater than the information dissemination of inter-group defection, $q_{D}$, while the information dissemination of defection in homogeneous societies, $k$, is in-between $q_{S}$ and $q_{D}$. Thus, social tensions between groups are more likely to arise than tensions within groups or tensions in homogeneous societies.

Proof. See Appendix.

Proposition 2 tells us that it is costlier for "strong" players to cheat on someone from their own group than on someone from the foreign group, due to the higher likelihood of the future match being informed.

\subsection{The Impact of Polarization}

Here we focus on the case of polarization between two groups, which is defined in the following way.

Definition 2 Polarization $\equiv 1-|w-v|$, where $w=$ population share of group $i, v=$ population share of group $j$.

The more similar the population shares of the two groups, the higher is the level of polarization in a given society. This is consistent with the commonly used definitions and measures of polarization (see Montalvo and Reynal-Querol, 2005).

The effect of group size on information dissemination after within-group defection is given by:

$$
\frac{\partial q_{S}}{\partial w}=k\left[\frac{-d_{i}^{2}}{w^{2}}+\frac{e_{i}^{2}}{(1-w)^{2}}\right]=k\left[\frac{e_{i}^{2} w^{2}-d_{i}^{2}(1-w)^{2}}{w^{2}(1-w)^{2}}\right]<0
$$

This derivative is negative, given our assumption G.9 above $\left(d_{i}>e_{i} \frac{w}{1-w} \Leftrightarrow P(S)>\right.$ $w)$, i.e., when people spend more than the proportional share of their time on intra-group interaction. This implies that increases in the size $w$ of a player's own group i lead to more within-group defection and a higher likelihood of intra-group tension for group i. An increase in $w$ corresponds however to a decrease in $v$ (as $v=1-w)$, lowering the likelihood of intra-group tension for the second group $\mathrm{j}$.

As mentioned above, for simplicity we always set for the comparative statics of intergroup interaction $d_{i}=d_{j} \equiv d, e_{i}=e_{j} \equiv e$. The impact of changes in $w$ on $q_{D}$ is given by:

$$
\frac{\partial q_{D}}{\partial w}=k\left[\frac{-d e}{w^{2}}+\frac{d e}{(1-w)^{2}}\right]=k\left[\frac{d e(2 w-1)}{w^{2}(1-w)^{2}}\right]
$$

The expression $\partial q_{D} / \partial w$ becomes positive for $w>0.5$. We shall now analyze the effects of an increase in polarization. 
Proposition 3 A marginal increase in polarization (decreasing the population share of the more numerous group and increasing the share of the less numerous group) results in a reduced level of intra-group tension inside the more numerous group and in a higher level of intra-group tension inside the smaller group.

Proof. In equation (17) we have $\partial q_{S} / \partial w<0$. Thus, increasing (resp., decreasing) $w$ results in a lower (resp., higher) $q_{S}$, and therefore a higher (resp., lower) likelihood of defection and social tension.

Intuitively, for the more numerous group, a decrease in its size increases the likelihood that fellow group members will become informed and thus increases the reputation cost of defection. The effect goes in the opposite direction for an increase in the group size of the less numerous group.

It is summarized below in proposition 4 how an increase in polarization affects $q_{D}$.

Proposition 4 A marginal increase in polarization results in a lower information dissemination of defection $q_{D}$ (for both groups) and accordingly in a higher level of intergroup tension.

Proof. For $w>0.5$ in equation (18) we have $\partial q_{D} / \partial w>0$, and for $w<0.5$ we have $\partial q_{D} / \partial w<0$. Thus, decreasing $w$ of the more numerous group results in a lower $q_{D}$ (as $\left.w>0.5 \Rightarrow \partial q_{D} / \partial w>0\right)$, whereas increasing $v$ of the smaller group results in a lower $q_{D}$ as well $\left(\right.$ as $\left.v<0.5 \Rightarrow \partial q_{D} / \partial w<0\right)$.

Intuitively, the information dissemination $q_{D}$ increases in the conditional probabilities of being informed, captured by equations (14) and (15). If the groups become very unequal in size, one of these two probabilities will sharply increase, given that the relative group sizes are in the denominator of these terms. This results in a large $q_{D}$. For high levels of polarization, both terms remain moderate in size, and $q_{D}$ stays low.

Note that while all other propositions of the paper remain unchanged for the special case of $e=0$, in the two propositions 4 and 8 (as discussed further below), polarization, resp. fractionalization only matter for inter-group defection when $e>0$. More precisely, for polarization the effect of $w$ on $q_{D}$ becomes smaller as $e$ decreases and finally becomes zero for $e=0$. This is intuitive: First, on a very general level, a reduced $e$ moves matching probabilities closer to proportionality. Clearly, the closer the matching probabilities are to proportionality, the less ethnic group structure matters (as under full proportionality information dissemination would be the same for defecting on any player in the society). Second, and more specifically, a decrease in $e$ corresponds to a society where different ethnic groups are less dependent on each other. As shown below, a drop in $e$ leads to more between-group social tensions. Hence, we can think of the effects of polarization and of a less inter-dependent society as being substitutes. One interesting empirical implication of this is that the effects of ethnic polarization (and fractionalization) are predicted to be largest in countries with more ethnic business monopolies (e.g., in many former colonies, cf. Horowitz, 2000). 


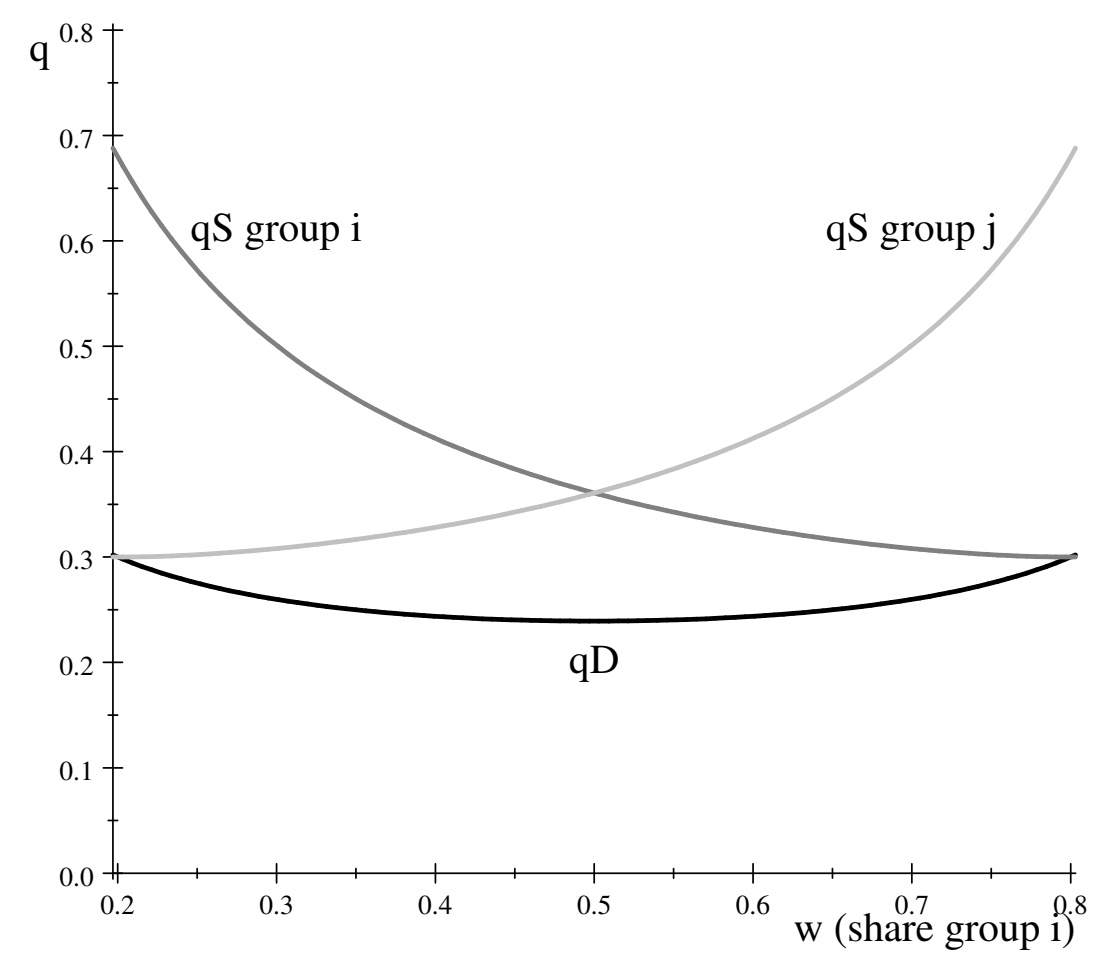

Figure 2: The impact of polarization

Figure 2 plots as a numerical example ${ }^{14}$ the levels of $q_{S}$ and $q_{D}$ for different levels of $w$. The values of $q_{D}$ are lower than the values of $q_{S}$, indicating that the likelihood of inter-group tension is higher than of intra-group tension. Further, the values of $q_{S}$ for some group are decreasing in its size, reflecting the lower reputation cost of defection when monitoring is "harder". Variable $q_{D}$ takes its lowest value at $w=0.5$ (maximum polarization). Hence, the more polarized a society, the greater is the likelihood of intergroup tension.

Our results on polarization increasing inter-group social tensions - which are a necessary condition for conflict - are consistent with Montalvo and Reynal-Querol's (2005) findings that ethnic polarization increases the risk of civil war.

\subsection{The Impact of Segregation}

The concept of segregation refers to the separation and lack of interaction between different groups. In our model we capture this by the net amount of time spent for exclusive within-group activities. The following definition applies: ${ }^{15}$

\footnotetext{
${ }^{14}$ The following parameter values have been used: $d_{i}=d_{j}=0.6, e_{i}=e_{j}=0.15$ and $k=0.3$.

${ }^{15}$ There are alternative ways of formally defining segregation. Remember, given assumption G.9 we have $P(S)>w$, i.e., people match more often than proportionally with other people from their group.
} 
Definition 3 Segregation $\equiv d_{i}-e_{i}$.

High values of $d_{i}$ (and low values of $e_{i}$ ) correspond to strong segregation, with only little inter-group interaction. Low values of $d_{i}$ (and relatively large values of $e_{i}$ ) indicate a very integrated society with a lot of inter-group interaction. In our comparative statics we will focus on the impact of an increase in $d_{i}$ (holding all other parameters constant). ${ }^{16}$

Remember that we had defined social tensions as the proportion of interactions that were conflicted, i.e., where defection occurred. This concept has so far been appropriate, as until now $d_{i}$ was constant. For the analysis of segregation, however, $d_{i}$ is not constant. Thus, we shall define a further concept that not only captures the likelihood of defection per interaction but also the number of interactions.

Definition 4 Social disputes $\equiv$ total number of defections.

Please note that "social disputes" $\equiv$ (total number of defections $)=($ social tensions $)$ $\times$ (number of interactions). Further, notice that an increase in $d_{i}$ leads to more intragroup and less inter-group matches, as $\partial P(S) / \partial d_{i}>0$ and $\partial P(D) / \partial d_{i}<0$.

We shall first establish the impact of changes in $d_{i}$ on the likelihood of intra-group tension.

$$
\frac{\partial q_{S}}{\partial d_{i}}=k\left[\frac{2 d_{i}}{w}-2\left(d_{i}+e_{i}\right)\right]=2 k\left[d_{i} \frac{1-w}{w}-e_{i}\right]>0
$$

The derivative $\partial q_{S} / \partial d_{i}$ is always positive, given our assumption of relatively more intense intra-group interaction $\left(d_{i}>e_{i} \frac{w}{1-w} \Leftrightarrow P(S)>w\right)$. Increases in $d_{i}$ result in increases in $q_{S}$, and thus lead to a reduced scope for intra-group tension. However, the impact of segregation on the total number of disputes is ambiguous. Although tensions are reduced, intra-group interaction becomes more frequent, as $\partial P(S) / \partial d_{i}>0$. The proposition below summarizes this trade-off:

Proposition 5 More segregation (i.e., a higher $d_{i}$ ) increases $q_{S}$ and thereby results in less intra-group tension. If the increase in $q_{S}$ is substantial, it can lead to initially conflicted interactions $\left(q_{S}<q^{*}\right)$ becoming peaceful $\left(q_{S} \geq q^{*}\right)$, thereby reducing total intra-group disputes. In contrast, for smaller increases in $q_{S}$, segregation can result in a higher level of total intra-group disputes by making intra-group interaction more frequent.

Proof. Follows from equation (19) and the discussion above.

This result is intuitive, as more intra-group interaction increases the monitoring of intra-group defection, reducing in this way social tensions. Now we shall analyze the effects of segregation on inter-group interactions.

One alternative definition of segregation that takes group sizes into account would be: Segregation $\equiv$ $P(S)-w=d_{i}(1-w)-e_{i} w$. However, the results of the comparative statics would be the same for this alternative definition, as the level of segregation would still be increasing in $d_{i}$, and decreasing in $e_{i}$.

${ }^{16}$ Our conclusions about the impact of segregation would be the same if we focused on a decrease in $e_{i}$ instead, as $\partial q_{S} / \partial e_{i}<0$ and $\partial q_{D} / \partial e>0$. 


$$
\frac{\partial q_{D}}{\partial d}=k\left[e\left(\frac{1}{w}+\frac{1}{1-w}\right)-2(d+e)\right]<0
$$

We obtain a negative derivative if $d \gg e .{ }^{17}$ Thus, given our assumption of relatively intense within-group interaction $(d \gg e)$, a rise in segregation leads, as players from different groups meet less often, to a lower information dissemination of defection $q_{D}$, and to more inter-group social tensions. At the same time, more segregation reduces inter-group interaction (as $\partial P(D) / \partial d<0$ ), making the overall effect on inter-group disputes ambiguous.

Proposition 6 Segregation increases inter-group tensions. The impact on inter-group disputes is ambiguous. Full segregation $(d=1, e=0)$ eliminates inter-group disputes entirely. For intermediate levels of segregation $(0<d<1)$, and initially conflicted inter-group interactions $\left(q_{D}<q^{*}\right)$, segregation reduces the occurrence of inter-group disputes by decreasing inter-group interaction (as already $q_{D}<q^{*}$, a further decrease in $q_{D}$ does not matter). For initially honest and peaceful inter-group interaction $\left(q_{D} \geq q^{*}\right)$, segregation can increase the scope for inter-group disputes, if the decrease in $q_{D}$ is large enough such that afterwards $q_{D}<q^{*}$ holds.

Proof. Follows from equation (20) and the reasoning discussed above.

This is in line with Varshney's (2001) and Jha's (2008) empirical findings for India that social tensions between ethnic groups are more likely to occur when social networks are intra-ethnic and when between-group interaction is rare (i.e., $d$ is large). In terms of policy recommendations, the model's predictions suggest that on the whole segregation is harmful, unless one is initially in a situation where defection dominates (i.e., $q_{D}<q^{*}$ ). In such settings, like recently in Bosnia, keeping the ethnic groups separate can reduce the total social disputes.

\section{Social Tensions in an n-group Framework}

For studying issues like polarization it made sense to limit ourselves to a 2-group framework that allowed for an unequal size of the groups. However, for analyzing fractionalization, as well as for testing the robustness of previous results, it is helpful to have a framework of n-groups of equal size each. Fractionalization is defined in the following way:

Definition 5 Fractionalization $\equiv 1-\frac{1}{r}$, where $r=$ number of groups.

Clearly, the level of fractionalization increases in the number of groups in the society. For intra-group defection in an n-group setting, the likelihood $q_{S}$ of the next period's

\footnotetext{
${ }^{17}$ The exact condition is $2 d>e \frac{w}{1-w}+e \frac{1-w}{w}$. This is similar to assumption G.9 and we shall assume that this always holds.
} 
opponent being informed is given by equation (21), which corresponds to $q_{S}$ in the 2 -group framework with $w=1 / r$, where $\mathrm{r}$ is the number of groups.

$$
q_{S}=k\left[\frac{d_{i}^{2}}{(1 / r)}+\frac{e_{i}^{2}}{1-(1 / r)}+1-\left(d_{i}+e_{i}\right)^{2}\right]
$$

As far as inter-group interaction is concerned, the main difference between the $\mathrm{n}$ group and the 2-group framework is that in the n-group case strangers from other groups do not all belong to the same other group. Thus, if a player from a group i defects on an opponent of a given group $j$, this will result in a relatively high probability that other players of group $\mathrm{j}$ are informed of the defection. However, players from another "foreign" group 1 will be as badly informed about the defection as the players of the "home" group i. Thus, it is necessary to take into account the probability of matching people from all different groups as well as their conditional probability of being informed. This is done in the Appendix. The likelihood of next period's match being informed about inter-group defection is given by equation (22).

$$
q_{D}=k\left[\frac{2 d e r}{r-1}+\frac{e^{2}(r-2) r}{(r-1)^{2}}+1-(d+e)^{2}\right]
$$

Propositions 5 and 6 , treating the effects of segregation on social tensions and disputes, also hold in a n-group framework if $\partial q_{S} / \partial d_{i}>0, \partial q_{D} / \partial d<0$. As $q_{S}$ is the same in the n-group as in the 2-group framework (with $w=1 / r$ ), the results on intra-group defection of the 2-group setting remain valid for n-groups. For inter-group defection, $\partial q_{D} / \partial d$ is displayed in equation (23).

$$
\frac{\partial q_{D}}{\partial d}=2 k\left[\frac{e}{r-1}-d\right]<0
$$

We obtain $\partial q_{D} / \partial d<0$ for $d>e$ and at least two groups, i.e., $r \geq 2$. Thus, the conclusions of proposition 6 in the previous section hold as well for the n-player framework (given the usual assumption G.9).

For assessing the impact of fractionalization on social tensions, we can focus on $\partial q_{S} / \partial r$ and $\partial q_{D} / \partial r$. For $\partial q_{S} / \partial r$, we can simply refer to the discussion of $\partial q_{S} / \partial w$ in the previous section. As $w=1 / r, \partial q_{S} / \partial r$ has just the opposite sign of $\partial q_{S} / \partial w$ before. Thus, $\partial q_{S} / \partial r>0$. This leads to proposition 7 .

Proposition 7 A marginal increase in fractionalization (i.e. increasing the number of groups, $r$, in the population) results in a higher level of $q_{S}$, and accordingly in a lower level of intra-group tensions.

Proof. See proof of proposition 3.

Intuitively, as groups become smaller, intra-group monitoring increases. For assessing the impact of fractionalization on inter-group tensions, we can focus on $\partial q_{D} / \partial r$. 


$$
\frac{\partial q_{D}}{\partial r}=2 e k\left[\frac{e-d(r-1)}{(r-1)^{3}}\right]<0
$$

The derivative $\partial q_{D} / \partial r$ becomes negative for $d>e$ and at least two groups, i.e., $r \geq 2$, which leads to proposition 8 .

Proposition 8 Fractionalization decreases $q_{D}$ and leads to more inter-group tensions.

Proof. Follows from equation (24).

This finding is intuitive, as the reduced relative size of the opponent's group in a fractionalized society makes it less likely to meet someone of that group in the future, decreasing thereby the reputation cost of defection.

As for polarization, the size of the effect of fractionalization on inter-group social tensions is increasing in $e$, and becomes zero for the special case of $e=0$. The intuition is similar, i.e., moves towards more proportional matching reduce the effects of group structure, and lack of group inter-dependence (low $e$ ) and fractionalization behave as substitutes.

This proposition is consistent with recent empirical evidence on ethnic fractionalization increasing social tensions, and thereby decreasing trust (e.g., Alesina and La Ferrara, 2002), participation in social activities (e.g., Alesina and La Ferrara, 2000) and public goods provision (e.g., Lind, 2007) and fueling conflicts between ethnic groups (e.g., Collier and Rohner, 2008).

\section{Class Cleavages and Social Tensions}

In this subsection we study whether and how our mechanism can apply also to class conflict. As expressed by Robinson (2001: 87), one key difference between ethnic and class divisions is that "while ethnic identity is immutable (or 'ascriptive'), class is not, since there is social mobility between capitalists and workers". ${ }^{18}$ In this subsection we focus on this difference and study the effects of mobility between groups.

Traditionally, much of the literature in political science regarded class divisions and vertical inequality as prime drivers of conflict (e.g., Gurr, 1970, focusing on relative deprivation). However, the econometric evidence in general has not supported these arguments (Cramer, 2003). As put by Besançon (2005: 393-4), "Political scientists, for decades, have argued that there is a nexus between economic inequality and political violence, yet these decades of studies have empirically challenged this view. Rarely have statistical studies resulted in a robust relationship between the two variables, and the results have often been contradictory and inconclusive".

Indeed, in the large cross-country panel studies, economic inequality either has been found to have no significant impact on social conflict (Fearon and Laitin, 2003; Collier

\footnotetext{
${ }^{18}$ In some cases ethnic identity is not completely immutable (cf. Posner, 2005, for Zambia), but switching from one ethnic group to another is in general very difficult (Horowitz, 2000).
} 
and Hoeffler, 2004), or its effect has been of indeterminate sign and not robust (Auvinen and Nafziger, 1999; Besançon, 2005). Of course, these results do not necessarily imply that there is no global link between inequality and social conflict, as these results could be due partly to the poor quality of inequality data (Cramer, 2003).

In contrast, the results are somewhat more affirmative for micro-econometric studies. While vertical inequality is still an insignificant predictor of social conflict in some studies (e.g., Ostby, 2008), there are quite a few papers where vertical inequality is significant in at least some (but usually not in all) of the specifications: Deininger, 2003, for Uganda; Justino, 2005, for India; Ostby et al., 2009, for 22 Sub-Saharan African countries; and Hidalgo et al., 2010, for Brazil.

Thus it seems fair to summarize the empirical findings of the literature on class conflict in the following two points: 1) In some contexts class divisions lead to social conflict, while in others not. 2) Economic inequality seems on average a less salient, resp. powerful predictor of social conflict than ethnic cleavages (Brubaker and Laitin, 1998; Horowitz, 2000; Esteban and Ray, 2008a). ${ }^{19}$

By making slight changes to the basic framework we can study class-related social tensions and generate predictions that can be compared to these empirical findings. Take now a society that is ethnically homogeneous, but where there are two classes, the workers and the bourgeoisie. As before, people tend to spend more than proportional amounts of time with people from their own class. This may be due to the use of status symbols or to differences in disposable income, which for example could account for the bourgeois residing in other areas and eating in other restaurants than workers do.

It would also be easy to include micro foundations in the model for inequality and social mobility. The source of persistent inequality could be capital-market imperfections and investment indivisibilities (Banerjee and Newman, 1993; Galor and Zeira, 1993, Ghatak and Jiang, 2002). In such settings typically it can be obtained that class and inequality persist: (dynasties of) workers remain workers and entrepreneurs remain entrepreneurs. If this was the end of the story, the framework of the previous sections would apply, with just the group names relabeled.

However, as far as class is concerned, with random stochastic shocks people can become socially mobile and move from one group to the other (Ghatak and Jiang, 2002). Given that our focus lies on explaining social tensions, we abstract from such micro foundations and simply assume that for class divisions with some probability $\varphi$ a given player changes her group (i.e., a poor person becomes rich, resp. a rich person becomes poor). ${ }^{20}$ Thus, the parameter $\varphi$ captures the level of social mobility.

For ethnic divisions, this switching probability $\varphi$ was simply $\varphi=0$. We could have assumed $\varphi$ to be positive for ethnic divisions as well, but it seems reasonable to think that for ethnic divisions $\varphi$ would be very small (Horowitz, 2000), and in any case smaller than for class divisions. It is easier to change income level than, for example, it is to

\footnotetext{
${ }^{19}$ Note that the empirical evidence on the relative salience of class versus ethnicity is still somewhat scarce. It would be useful to have more micro studies that horse-race identification strategies for inequality and ethnicity.

${ }^{20}$ For simplicity, we assume that players (potentially) switch groups right after their first period interaction and before information dissemination. The results are robust to alternative timing assumptions.
} 
change skin color.

As before for the comparative statics of inter-group interaction, we assume for simplicity $d_{i}=d_{j} \equiv d, e_{i}=e_{j} \equiv e$. Further, we make the simplifying assumption that the social mobility is similar in both directions (i.e., $\varphi$ is the same for both groups). We also assume that social mobility is not extreme and that players are more likely to stay in their group than to switch groups, i.e., $\varphi<1 / 2$.

Now the probabilities of meeting a player belonging to the same group i, $P(S)$, resp. of meeting a player belonging to the other group, $P(D)$, become:

$$
\begin{gathered}
P(S)=(1-\varphi)(d+(1-d-e) w)+\varphi(e+(1-d-e) w) \\
P(D)=(1-\varphi)(e+(1-d-e)(1-w))+\varphi(d+(1-d-e)(1-w))
\end{gathered}
$$

where $\varphi=$ probability of changing groups.

After reformulation, we can express $\widetilde{d} \equiv(1-\varphi) d+\varphi e$ and $\widetilde{e} \equiv(1-\varphi) e+\varphi d$. Note also that $\widetilde{d}+\widetilde{e}=d+e$. Hence we can re-write $P(S)$ and $P(D)$ as:

$$
\begin{gathered}
P(S)=\widetilde{d}+(1-\widetilde{d}-\widetilde{e}) w \\
P(D)=\widetilde{e}+(1-\widetilde{d}-\widetilde{e})(1-w)
\end{gathered}
$$

Note that $P(S)=1-P(D)$. Let us focus as before on situations where players are always more than proportionally likely to match with someone from their home group, i.e., where $P(S)>w$. This always holds as long as $d>e \frac{w-\varphi}{1-w-\varphi}$.

Note that $P(m \mid S), P(m \mid D), q_{S}$, and $q_{D}$ are computed analogously as before, simply using now $\widetilde{d}$ and $\widetilde{e}$, instead of $d$ and $e$. Hence, comparing the effects of class divisions with those of ethnic divisions becomes straightforward. ${ }^{21}$

Proposition 9 The likelihood of social tensions between groups, resp. classes is ceteris paribus higher in equal, but ethnically divided societies than in unequal, but ethnically homogeneous societies. If a society has only a moderate conflict potential (i.e., when $q^{*}$ is not too large) this conclusion also holds for the total number of disputes.

Proof. As $\varphi>0$ and $d>e$, we have that $\widetilde{d}<d$ (and $\widetilde{e}>e$, which has the same effects). Further, from equation (20) we know that $\partial q_{D} / \partial d<0$. Hence in class-divided societies $q_{D}$ is larger and the likelihood of social tensions between groups smaller. As $\partial P(D) / \partial d<0, \widetilde{d}<d$ implies a larger inter-group matching intensity in class-divided

\footnotetext{
${ }^{21}$ In this section we focus on the role of social mobility. Note that we could include another channel that would make class tensions less likely: If there was some complementarity in production or in trade between bourgeois and workers, this could imply that they match more often than people from different ethnic groups do. Hence, $d$ would be relatively smaller and $e$ larger for unequal, but ethnically homogenous societies, which would increase $q_{D}$ and hence decrease the likelihood of social tensions between classes.
} 
societies, which potentially could increase the number of disputes, as in the analysis of segregation. However, this will not be the case as long as $q^{*}$ is small.

Our framework also allows us to generate predictions on the impact of social mobility.

Proposition 10 Increasing social mobility has qualitatively analogous effects to decreasing segregation (which are described in detail in propositions 5 and 6). In particular, more social mobility leads to more social tensions within classes and less social tensions between classes.

Proof. We have $\partial \widetilde{d} / \partial \varphi<0$ (and $\partial \widetilde{e} / \partial \varphi>0$ ), the effects of which are analyzed in the proofs of propositions 5 and 6 .

\section{Conclusion}

This paper has examined how group cleavages matter for the emergence of social tensions. It has shown how the reputation cost of future opponents being informed about defection can enforce cooperation. This reputation cost depends critically on the group structure, and the relatively intense within-group matching explains why between-group tensions are more frequent than within-group social tensions are.

Increases in polarization have been found to increase intra-group tensions in the less numerous group, and decrease tensions inside the more numerous group. Increased polarization also leads to more social tensions between groups.

The impact of increased segregation is less clear-cut, as segregation affects not only the level of social tensions, but also the frequency of interaction. If the effect of segregation on $q_{S}$ is large, it can reduce intra-group disputes, whereas otherwise it can result in a rise of intra-group disputes. Inter-group disputes may be increased by segregation if initially relations are peaceful, while segregation can reduce inter-group disputes if initially interactions are conflicted.

Fractionalization has been found to decrease social tensions within groups and increase social tensions between groups.

We have also extended the model to study class rather than ethnic cleavages, and found that social mobility makes social tensions between classes less likely than between ethnic groups.

The findings here can account for recent empirical evidence on the effects of ethnic polarization, fractionalization and segregation on trust, civic participation, public good provision and on ethnic conflicts. Further empirical research on group identity and social tensions is encouraged.

\section{References}

[1] Alesina, Alberto, and Eliana La Ferrara. (2000). "Participation in Heterogeneous Communities", Quarterly Journal of Economics, 115, 847-904. 
[2] Alesina, Alberto, and Eliana La Ferrara. (2002). "Who trusts others?", Journal of Public Economics, 85, 207-34.

[3] Alesina, Alberto, Reza Baqir, and William Easterly. (1999). "Public Goods and Ethnic Divisions", Quarterly Journal of Economics, 114, 1243-84.

[4] Anderson, Siwan, Jean-Marie Baland, and Karl Ove Moene. (2009). "Enforcement in Informal Saving Groups", Journal of Development Economics, 90, 14-23.

[5] Auvinen, Juha, and E. Wayne Nafziger. (1999). "The Sources of Humanitarian Emergencies", Journal of Conflict Resolution, 43, 267-90.

[6] Banerjee, Abhijit, and Andrew Newman. (1993). "Occupational Choice and the Process of Development", Journal of Political Economy, 101, 274-98.

[7] Besançon, Marie. (2005). "Relative Resources: Inequality in Ethnic Wars, Revolutions, and Genocides", Journal of Peace Research, 42, 393-415.

[8] Bates, Robert. (2010). Prosperity and Violence: The Political Economy of Development, New York, W.W. Norton, Second edition.

[9] Boehm, Christopher. (1986). Blood Revenge: The Enactment and Management of Conflict in Montenegro and Other Tribal Societies, Philadelphia, University of Pennsylvania Press.

[10] Botticini, Maristella. (2000). "A Tale of 'Benevolent' Governments: Private Credit Markets, Public Finance, and the Role of Jewish Lenders in Medieval and Renaissance Italy", Journal of Economic History, 60, 164-89.

[11] Brubaker, Rogers, and David Laitin. (1998). "Ethnic and Nationalist Violence", Annual Review of Sociology, 24, 423-52.

[12] Caselli, Francesco, and Wilbur John Coleman II. (2010). "On the Theory of Ethnic Conflict", mimeo, London School of Economics and Duke University.

[13] Coleman, James. (1988). "Social Capital in the Creation of Human Capital", American Journal of Sociology, 94, S95-S120.

[14] Collier, Paul, and Anke Hoeffler. (2004). "Greed and grievance in civil war", Oxford Economic Papers, 56, 563-95.

[15] Collier, Paul, Anke Hoeffler, and Dominic Rohner. (2009). "Beyond Greed and Grievance: Feasibility and Civil War", Oxford Economic Papers, 61, 1-27.

[16] Collier, Paul, and Dominic Rohner. (2008). "Democracy, Development, and Conflict", Journal of the European Economic Association, 6, 531-40.

[17] Cramer, Christopher. (2003). "Does Inequality Cause Conflict?", Journal of International Development, 15, 397-412. 
[18] Dasgupta, Partha. (1988). "Trust as a Commodity" in Diego Gambetta (ed.), Trust: Making and Breaking Cooperative Relations, Oxford, Basil Blackwell.

[19] Dasgupta, Partha. (1999). "Economic Progress and the Idea of Social Capital" in Partha Dasgupta and Ismail Serageldin (eds.), Social Capital: A Multifaceted Perspective, Washington, World Bank.

[20] Dasgupta, Partha. (2005). "Economics of Social Capital", Economic Record, 81, S2-S21.

[21] Deininger, Klaus. (2003). "Causes and consequences of civil strife: micro-level evidence from Uganda", Oxford Economic Papers, 55, 579-606.

[22] Diez Medrano, Juan. (1994). "The Effects of Ethnic Segregation and Ethnic Competition on Political Mobilization in the Basque Country, 1988", American Sociological Review, 59, $873-89$.

[23] Dixit, Avinash. (2003). "Trade Expansion and Contract Enforcement", Journal of Political Economy, 111, 1293-317.

[24] Dustmann, Christian, Albrecht Glitz, and Uta Schönberg. (2010). "Referral-based Job Search Networks", mimeo, University College London.

[25] Ellingsen, Tanja. (2000). "Colorful Community or Ethnic Witches' Brew?", Journal of Conflict Resolution, 44, 228-49.

[26] Esteban, Joan, and Debraj Ray. (1999). "Conflict and Distribution", Journal of Economic Theory, 87, 379-415.

[27] Esteban, Joan, and Debraj Ray. (2008a). "On the Salience of Ethnic Conflict", American Economic Review, 98, 2185-202.

[28] Esteban, Joan, and Debraj Ray. (2008b). "Polarization, Fractionalization and Conflict", Journal of Peace Research, 45, 163-82.

[29] Esteban, Joan, and Debraj Ray. (2009). "Linking Conflict to Inequality and Polarization", forthcoming in the American Economic Review.

[30] Evans-Pritchard, Edward. (1940). The Nuer, Oxford, Clarendon Press.

[31] Fearon, James, and David Laitin. (1996). "Explaining Interethnic Cooperation", American Political Science Review, 90, 715-35.

[32] Fearon, James, and David Laitin. (2003). "Ethnicity, Insurgency, and Civil War", American Political Science Review, 97, 75-90.

[33] Galor, Oded, and Joseph Zeira. (1993). "Income Distribution and Macroeconomics", Review of Economic Studies, 60, 35-52.

[34] Ghatak, Maitreesh, and Neville Nien-Huei Jiang. (2002). "A simple model of inequality, occupational choice, and development", Journal of Development Economics, 69, 205-26. 
[35] Greif, Avner, Paul Milgrom, and Barry Weingast. (1994). "Coordination, Commitment, and Enforcement: The Case of the Merchant Guild", Journal of Political Economy, 102, $745-76$.

[36] Gurr, Ted. (1970). Why Men Rebel, Princeton, Princeton University Press.

[37] Gurr, Ted. (1993). "Why Minorities Rebel: A Global Analysis of Communal Mobilization and Conflict since 1945", International Political Science Review, 14, 161-201.

[38] Hegre, Havard, Tanja Ellingsen, Scott Gates, and Nils Petter Gleditsch. (2001). "Toward a Democratic Civil Peace? Democracy, Political Change, and Civil War, 1816-1992", American Political Science Review, 95, 33-48.

[39] Hidalgo, F. Daniel, Suresh Naidu, Simeon Nichter, and Neal Richardson. (2010). "Economic Determinants of Land Invasions", Review of Economics and Statistics, 92, 505-23.

[40] Horowitz, Donald. (1973). "Direct, Displaced and Cumulative Ethnic Aggression", Comparative Politics, 6, 1-16.

[41] Horowitz, Donald. (2000) [1985]. Ethnic Groups in Conflict, Berkeley, University of California Press, Second Edition.

[42] Horowitz, Donald. (2001). The Deadly Ethnic Riot, Berkeley, University of California Press.

[43] Jha, Saumitra. (2008). "Trade, Institutions and Religious Tolerance: Evidence from India", mimeo, Stanford University.

[44] Justino, Patricia. (2005). "Redistribution, Inequality and Political Conflict", mimeo, University of Sussex.

[45] Kandori, Michihiro. (1992). "Social Norms and Community Enforcement", Review of Economic Studies, 59, 63-80.

[46] Knack, Stephen, and Philip Keefer. (1997). "Does Social Capital Have An Economic Payoff? A Cross-Country Investigation", Quarterly Journal of Economics, 112, 1251-88.

[47] Lester, Ashley. (2005). "Essays in the Theory of Economic Growth", PhD Thesis, MIT, Chapter 1.

[48] Lind, Jo Thori. (2007). "Fractionalization and the size of government", Journal of Public Economics, 91, 51-76.

[49] Luttmer, Erzo. (2001). "Group Loyalty and the Taste for Redistribution", Journal of Political Economy, 109, 500-28.

[50] Miguel, Edward, and Mary Kay Gugerty. (2005). "Ethnic diversity, social sanctions, and public goods in Kenya", Journal of Public Economics, 89, 2325-68.

[51] Montalvo, José, and Marta Reynal-Querol. (2005). "Ethnic Polarization, Potential Conflict, and Civil Wars", American Economic Review, 95, 796-815. 
[52] Nowak, Martin, and Karl Sigmund. (1998). "Evolution of indirect reciprocity by image scoring", Nature, 393, 573-7.

[53] Olzak, Susan, Suzanne Shanahan, and Elizabeth McEneaney. (1996). "Poverty, Segregation, and Race Riots: 1960 to 1993", American Sociological Review, 61, 590-613.

[54] Ostby, Gudrun. (2008). "Polarization, Horizontal Inequalities and Violent Civil Conflict", Journal of Peace Research, 45, 143-62.

[55] Ostby, Gudrun, Ragnhild Nordas, and Jan Ketil Rod. (2009). "Regional Inequalities and Civil Conflict in Sub-Saharan Africa", International Studies Quarterly, 53, 301-24.

[56] Posner, Daniel. (2005). Institutions and Ethnic Politics in Africa, Cambridge, Cambridge University Press.

[57] Putnam, Robert, with Robert Leonardi and Raffaella Nanetti. (1993). Making Democracy Work: Civic Traditions in Modern Italy, Princeton NJ, Princeton University Press.

[58] Rauch, James. (2001). "Business and Social Networks in International Trade", Journal of Economic Literature, 39, 1177-203.

[59] Reynal-Querol, Marta. (2002). "Ethnicity, Political Systems, and Civil Wars", Journal of Conflict Resolution, 46, 29-54.

[60] Robinson, James. (2001). "Social identity, inequality and conflict", Economics of Governance, 2, 85-99.

[61] Sambanis, Nicholas. (2000). "Partition as a Solution to Ethnic War: An Empirical Critique of the Theoretical Literature", World Politics, 52, 437-83.

[62] Sambanis, Nicholas. (2001). "Do Ethnic and Nonethnic Civil Wars Have the Same Causes?", Journal of Conflict Resolution, 45, 259-82.

[63] Strulik, Holger. (2008). "Social Composition, Social Conflict and Economic Development", Economic Journal, 118, 1145-70.

[64] Tambiah, Stanley. (1990). "Presidential Address: Reflections on Communal Violence in South Asia", Journal of Asian Studies, 49, 741-60.

[65] Tirole, Jean. (1996). "A Theory of Collective Reputations (with Applications to the Persistence of Corruption and to Firm Quality)", Review of Economic Studies, 63, 1-22.

[66] Vanhanen, Tatu. (1999). "Domestic Ethnic Conflict and Ethnic Nepotism: A Comparative Analysis", Journal of Peace Research, 36, 55-73.

[67] Varshney, Ashutosh. (2001). "Ethnic Conflict and Civil Society: India and Beyond", World Politics, 53, 362-98.

[68] Vigdor, Jacob. (2004). "Community composition and collective action: Analyzing initial mail response to the 2000 census", Review of Economics and Statistics, 86, 303-12. 


\section{Appendix: Proofs and Derivations}

\section{Proof of lemma 3:}

It follows from assumption G.6 that without any a priori knowledge of the opponent the beliefs are such that $\mu=p<\mu^{*}$. We know that weak players would always prefer $\mathrm{a}=\mathrm{c}$ to $\mathrm{a}=\mathrm{o}$ as equation (1) always holds for $\mu=p<\mu^{*}$. Assumption G.4 implies that in a one-shot game, $\pi_{c c}^{w}>\pi_{d c}^{w}, \pi_{c d}^{w}>\pi_{d d}^{w}$. Hence, in a one-shot game a=c would be the best reply.

The only thing that could prevent a weak player from playing $\mathrm{a}=\mathrm{c}$ is the "shadow of the future", i.e., if $\mathrm{a}=\mathrm{o}$ or $\mathrm{a}=\mathrm{d}$ were to result in a more favorable reputation in the second period. Clearly, as shown in lemma 1 strong players always defect in period 2 independently of their beliefs. Also, both actions $\mathrm{a}=\mathrm{c}$ and $\mathrm{a}=\mathrm{o}$ lead to a signal $\sigma=0$ for the future opponent in period 2 of life.

We shall prove by contraction that $\mathrm{a}=\mathrm{d}$ cannot be preferred to $\mathrm{a}=\mathrm{c}$. Imagine that $\mathrm{a}=\mathrm{d}$ were to be preferred to $\mathrm{a}=\mathrm{c}$ in the first period. This can only be the case if $\mathrm{a}=\mathrm{d}$ lowers the opponent's $\mu$ in period 2 of life. Given that $\mathrm{a}=\mathrm{c}$ leads to a signal $\sigma=0$, $\mathrm{a}=\mathrm{d}$ can only possibly be preferable if it results in a signal $\sigma=1$. This can only be the case if a given weak player defects on an opponent who cooperates. However, given that all weak players are identical, if one weak player were to have incentives to play $\mathrm{a}=\mathrm{d}$, all others would play $\mathrm{a}=\mathrm{d}$ as well. If both matching players defect, the resulting signal is $\sigma=0$. Thus, a signal $\sigma=1$ is only consistent with a weak player choosing a=d and matching with a strong type playing $a=c$. However, if all weak players choose $a=d$, the best reply for strong players would be $a=d$ rather than $a=c$ (playing $a=d$ in such $a$ context would lead to a higher payoff for the strong player and not alter her reputation for period 2).

\section{Proof of proposition 2:}

The probability $P(S)_{i}$ can be expressed as $P(S)_{i}=d_{i}+\left(1-d_{i}-e_{i}\right) w \equiv D_{i}$, implying $P(D)_{i}=1-D_{i}$. Analogously, $P(S)_{j}=d_{j}+\left(1-d_{j}-e_{j}\right)(1-w) \equiv D_{j}$ and $P(D)_{j}=1-D_{j}$. Given our assumptions above, we know that $D_{i}>w$ and $D_{j}>1-w$.

After reformulation, equation (10) yields for group i $q_{S}=k\left[\frac{D_{i}^{2}}{w}+\frac{\left(1-D_{i}\right)^{2}}{(1-w)}\right]$ and $q_{D}=k\left[D_{i} \frac{\left(1-D_{j}\right)}{w}+\left(1-D_{i}\right) \frac{D_{j}}{(1-w)}\right]$ (all results are identical for group $\mathrm{j}$ ).

Equation (7) implies that a higher probability of the next match being informed, $q$, reduces the incentives for defection. It follows that intra-group tensions are lower than inter-group tensions if $q_{S}>q_{D}$. This is the case if condition (A.1) holds.

$$
q_{S}>q_{D} \Leftrightarrow \frac{D_{i}^{2}}{w}+\frac{\left(1-D_{i}\right)^{2}}{(1-w)}>D_{i} \frac{\left(1-D_{j}\right)}{w}+\left(1-D_{i}\right) \frac{D_{j}}{(1-w)}
$$

After reformulation this condition becomes $D_{i}\left(D_{i}+D_{j}-1\right)>w\left(D_{i}+D_{j}-1\right)$, which always holds as long as $D_{i}>w$ and $D_{j}>1-w$.

Intra-group tensions are lower than social tensions in homogeneous societies if $q_{S}>q$. We have $q=k$ and $q_{S}=k\left[\frac{D_{i}^{2}}{w}+\frac{\left(1-D_{i}\right)^{2}}{(1-w)}\right]$. Setting $k\left[\frac{D_{i}^{2}}{w}+\frac{\left(1-D_{i}\right)^{2}}{(1-w)}\right]>k$, we obtain 
after reformulation condition (A.2), which always holds for $D_{i} \neq w$ (this is the case for $\left.D_{i}>w\right)$.

$$
q_{S}>q \Leftrightarrow\left(D_{i}-w\right)^{2}>0
$$

Inter-group tensions are greater than tensions in a homogeneous society if:

$$
q_{D}<q \Leftrightarrow D_{i} \frac{\left(1-D_{j}\right)}{w}+\left(1-D_{i}\right) \frac{D_{j}}{(1-w)}<1
$$

This condition holds if $\left(D_{j}+w-1\right)\left(D_{i}-w\right)>0$, which is the case for $D_{i}>w$ and $D_{j}>1-w$.

\section{Computing $q_{D}$ for n-groups:}

For inter-group defection, the overall probability, $q_{D}$, of the next match being informed is given by equation (A.4).

$$
q_{D}=P(S) P(m \mid S)+P(C) P(m \mid C)+P(T) P(m \mid T)
$$

where, $P(S)$ = Probability of meeting a player belonging to the same group, $P(m \mid S)$ $=$ Probability of the match being informed, conditional on being from the same group, $P(C)=$ Probability of meeting a player belonging to the group of the present opponent, $P(m \mid C)=$ Probability of the match being informed, conditional on being from the group of the present opponent, $P(T)=$ Probability of meeting a player belonging to some third group, $P(m \mid T)=$ Probability of the match being informed, conditional on being from some third group.

As before, the likelihood of matching with a player of one's own group equals

$$
P(S)=d+(1-d-e) \frac{1}{r}
$$

where $r=$ number of groups. For simplicity we focus in the treatment of n-groups on the same $d$ and $e$ for all groups.

The probability of matching in a given period with someone of the group of last period's betrayed opponent $(\mathrm{C})$ or some third group $(\mathrm{T})$ equals, respectively:

$$
\begin{gathered}
P(C)=\frac{e}{r-1}+(1-d-e) \frac{1}{r} \\
P(T)=e\left[\frac{r-2}{r-1}\right]+(1-d-e) \frac{r-2}{r}
\end{gathered}
$$

The conditional probabilities are as follows:

$$
P(m \mid S)=P(m \mid T)=\frac{\frac{e}{r-1}+(1-d-e) \frac{1}{r}}{\frac{1}{r}} k
$$




$$
P(m \mid C)=\frac{d+(1-d-e) \frac{1}{r}}{\frac{1}{r}} k
$$

Introducing equations (A.5) to (A.9) in (A.4), we obtain:

$$
q_{D}=k\left[\frac{2 d e r}{r-1}+\frac{e^{2}(r-2) r}{(r-1)^{2}}+1-(d+e)^{2}\right]
$$

